\title{
Can Stirrups Suppress Size Effect on Shear Strength of RC Beams?
}

\author{
Qiang Yu ${ }^{1}$ and Zdeněk P. Bažant, Hon.M.ASCE ${ }^{2}$
}

\begin{abstract}
This paper demonstrates the size effect on the shear strength of reinforced concrete (RC) beams with stirrups and does so in two separate and independent ways: (1) by fracture mechanics, based on finite-element analysis calibrated by a large beam test; and (2) by purely statistical analysis in which a newly assembled database of 234 tests is filtered to eliminate spurious size effects caused by nonuniformity of secondary influencing parameters. Both ways show that stirrups, whether minimum or heavier, cannot suppress the size effect completely, although they can mitigate it significantly for beam depth $d<1 \mathrm{~m}(39.4 \mathrm{in}$.). The effect of stirrups is to push the size effect curve in logarithmic scale into sizes larger by about one order of magnitude. For beam depths $d<0.5 \mathrm{~m}, 1,2$, and $6 \mathrm{~m}(19.7,39.4,78.7$, and $236.2 \mathrm{in}$.), the percentages of beams whose shear strength is below the code limit are calculated as 3.5, 6.5, 15.7, and 55.1\%, respectively. The corresponding failure probabilities are $10^{-6}, 10^{-5}, 10^{-4}$, and $10^{-3}$, whereas $10^{-6}$ is the generally accepted standard for a tolerable maximum in risk analysis. It follows that, for beams with stirrups having depth $>1 \mathrm{~m}$ (39.4 in.), the size effect cannot be neglected. DOI: 10.1061/(ASCE)ST.1943-541X.0000295. () 2011 American Society of Civil Engineers.
\end{abstract}

CE Database subject headings: Concrete; Design; Size effect; Reinforcement; Failures; Shear strength; Probability; Concrete beams.

Author keywords: Concrete design; Size effect; Shear reinforcement; Failure probability; RC beams.

\section{Introduction}

Beginning with the pioneering tests of Kani (1967) and Bhal (1968), significant size effect on the shear strength of geometrically scaled reinforced concrete (RC) beams without stirrups has been experimentally demonstrated by many studies, particularly Iguro et al. (1985), Bažant and Kazemi (1991), Walraven and Lehwalter (1994), Shioya and Akiyama (1994), Podgorniak-Stanik (1998), Angelakos et al. (2001), and Lubell et al. (2004). Furthermore, indirect experimental evidence of size effect in absence of stirrups has been statistically extracted from large databases (Bažant and Kim 1984; Bažant and Sun 1987; Bažant and Yu 2005a, b, 2008) assembled from tests which were not motivated by size effect and were performed in various laboratories using various concretes, shear spans and steel ratios. Parallel theoretical studies led to a size effect formula for the shear strength of beams without stirrups (Bažant 1984; Bažant and Kim 1984) justified by fracture mechanics and asymptotic matching.

Early on, Okamura and Higai (1980) proposed for beam shear a size effect formula justified by Weibull statistical theory (Weibull $1939,1951)$. Because Weibull's theory was the only theory of size effect available at that time, the formula was promptly adopted for the Japanese design code (JSCE 1986). This theory, however, was later shown (Bažant and Xi 1991; Bažant and Planas 1998; RILEM

${ }^{1}$ Postdoctoral Research Associate, Northwestern Univ., CEE, 2145 Sheridan Rd., Evanston, IL 60208. E-mail: qiangyu@northwestern.edu

${ }^{2}$ McCormick Institute Professor and W.P. Murphy Professor of Civil Engineering and Materials Science, Northwestern Univ., CEE, 2145 Sheridan Rd., Evanston, IL 60208 (corresponding author). E-mail: z-bazant@northwestern.edu

Note. This manuscript was submitted on December 8, 2009; approved on August 20, 2010; published online on April 15, 2011. Discussion period open until October 1, 2011; separate discussions must be submitted for individual papers. This paper is part of the Journal of Structural Engineering, Vol. 137, No. 5, May 1, 2011. (CASCE, ISSN 0733-9445/2011/5-607$617 / \$ 25.00$.
2004; Bažant 2005) to be inapplicable to failures occurring after stable growth of large cracks, typical of shear failure of RC beams, and to greatly underestimate the size effect for large beams. On a purely empirical basis, the European Concrete Committee (CEB, later "fib") adopted in 1990 (CEB 1990) another simple formula that was later also found to greatly underestimate the size effect for very large beams.

Until a few years ago, the rationale for not introducing the size effect into the ACI code was that no tests of three-point loaded beams had shown a strength less than that required by the code. In other words, the safety margins implied by the design code were thought to provide adequate protection from the size effect. What further helped was the covert understrength factor (Bažant and $\mathrm{Yu}$ 2006), consisting in the little known fact that the shear design formula for beams without stirrups was set at about 55\% below the mean of the test data. However, two recent findings undermined this rationale:

1. It was shown that, if the size effect is ignored, an increase of beam depth from $0.3 \mathrm{~m}$ (12 in.) to $1 \mathrm{~m}$ (39.4 in.) raises the shear failure probability of beams without stirrups from $10^{-6}$ to $10^{-3}$ per lifetime (Bažant and Yu 2009). $10^{-6}$ is a value generally considered by safety experts as the maximum tolerable for buildings, bridges, aircraft, and ships (NKB 1978; Melchers 1987; Duckett 2005). But $10^{-3}$ means that one among 1,000 very large beams is expected to fail, which is unacceptable.

2. Increasing the beam depth above $1 \mathrm{~m}$, the failure probability, of course, gets still higher. So it is no surprise that one test of a $1.89 \mathrm{~m}$ (74.4 in.) deep beam without stirrups at the University of Toronto (Podgorniak-Stanik 1998; Angelakos et al. 2001), showed a shear strength that was $50 \%$ lower than the prediction of the current ACI code (ACI 2008).

After these alarming findings, it was generally agreed that some change in ACI-318 chapter 11 was inevitable. However, diverse conflicting proposals were put forward. One was the proposal unanimously endorsed in 2006 by ACI Committee 446 (Fracture 
Mechanics; see Bažant et al. 2007). Several other proposals for taking the size effect in beam shear into account were made by members of ACI Committee 445 (1998) (Shear and Torsion).

In the face of unresolved conflict, it was simply decided to introduce into ACI 318 (ACI 2008) [Sec. 11.4.6.1(d)] a mandatory requirement that $\mathrm{RC}$ beams deeper than $25 \mathrm{~cm}$ (10 in.) must contain at least the specified minimum amount of stirrups. A tacit premise was a widespread conviction that the use of stirrups, even the minimum stirrups, eliminates the size effect (Lubell et al. 2004). However, is this conviction justified? Answering this question is the objective of this paper.

Providing the answer solely by targeted experiments is not practically feasible because no realistic funding would suffice for testing a statistically significant number of beams with stirrups within the entire size range of interest (up to at least $6 \mathrm{~m}$ depth, possibly $15 \mathrm{~m}$ ). The answer is sought here in two separate ways:

1. By computational simulation using a theoretically wellfounded material model that agrees with broad experimental evidence-particularly, microplane model M4 (Bažant et al. 2000; Caner and Bažant 2000), combined with the crack-band model, which takes into account in an objective manner the localization of distributed damage caused by cracking and eliminates the spurious mesh sensitivity. A computer program using this method will be calibrated by the only available test of a large beam with stirrups.

2. By statistical analysis of a new large database properly filtered to overcome a bias caused by nonuniform sampling of the influencing parameters.

To justify the optimistic view that stirrups eliminate the size effect, it has been thought that the stirrups prevent the loss of stress transfer by aggregate interlock. On the basis of small beam tests, it has been believed that because the diagonal shear crack cannot open widely, significant stresses must be transferred across the diagonal crack (ACI 1998). However, the computations that follow show that, for large beams, this is true only at macrocrack initiation, which occurs far below the maximum load. By the time the maximum load is reached, the stresses transmitted across the diagonal crack in beams of depth $d>6 \mathrm{~m}$ or 236.2 in. support less than $5 \%$ of the total shear force.

\section{Current Design Approach and Size Effect}

The current standard ACI 318 (ACI 2008) specifies for RC beams with shear reinforcement, whether minimum or heavier, a sizeindependent shear strength:

$$
v_{n}=\frac{V_{n}}{b d}=v_{c}+v_{s}=2 \sqrt{f_{c}^{\prime}}+\frac{A_{v} f_{y t}}{b s}(\sin \alpha+\cos \alpha)
$$

(valid in the units of $\mathrm{lb}$, psi, and in.). Here, $V_{n}=$ total shear capacity of the beam; $v_{c}, v_{s}=$ shear strength provided by concrete and by shear reinforcement (stirrups), respectively; $f_{c}^{\prime}=$ specified compressive strength of concrete; $A_{v}=$ cross section area of the shear reinforcement with spacing $s ; f_{y t}=$ specified yield strength of shear reinforcement, $b=$ width of the concrete beam, $d=$ beam depth measured from the top surface to the centroid of the flexural reinforcement at the bottom, and $\alpha=$ angle between the stirrups and longitudinal axis. For vertically positioned stirrups, $v_{s}=A_{v} f_{y t} / b s=\rho_{s} f_{y t}$. The shear reinforcement ratio is defined as $\rho_{s}=A_{v} / b s$.

Eq. (1) neglects the size effect. But the size effect is endemic to concrete. This is a quas-ibrittle material in which a fully developed

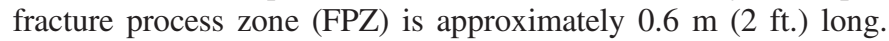
When the structure is so small that this length is comparable to the cross section dimensions, the failure is ductile (or quasi-plastic), with no size effect. On the other hand, when the structure is so large that the FPZ length is negligible, the failure is almost perfectly brittle, with a strong size effect (Bažant and Planas 1998; RILEM 2004; Bažant 2005).

According to quasibrittle (or cohesive) fracture mechanics, concrete exhibits size effects of two types: (1) The size effect in failures occurring at macro-crack initiation, which is typical of plain concrete and does not apply here; and (2) the size effect in failures occurring after large stable crack growth, which is typical of reinforced concrete, especially beam shear. According to fracture mechanics, the latter is caused by the energy release associated with stress redistribution caused by a large crack and approximately follows Bažant's (1984) energetic size effect law:

$$
v=\frac{v_{0}}{\sqrt{\left(1+d / d_{0}\right)}}
$$

in which parameters $v_{0}$ and $d_{0}$ depend only on structure geometry. This formula has been shown to apply to beams without stirrups (Bažant and Yu 2005a, b; Bažant et al. 2007) and may logically be expected to apply also to beams with stirrups, albeit with very different parameters.

\section{Current Knowledge of Behavior of Beams with Stirrups}

Depending on the shear span ratio $a / d$ (where $d=$ beam depth, and $a=$ shear span which, for 3-point loading, coincides with the half span), two categories of reinforced concrete beams with significantly different failure behaviors are distinguished: (1) deep (or short) beams, and (2) slender beams. The transition between these two categories is continuous, centered approximately at $a / d=2$.

The deep beams act, at maximum load, similarly to a tied arch. The error of the hypothesis of plane cross sections is much greater than it is for slender beams, partly because large diagonal cracks emanate from the supports. It is generally accepted (ACI-ASCE 1998) that the shear capacity of deep beams can be predicted according to the strut-and-tie model (STM), previously called the "truss model" (Ritter 1889; Mörsch 1922). But this can be true only as long as the stress in the imagined "compression strut" is much less than the compressive strength of concrete, $f_{c}^{\prime}$. If the deep beam fails by compression crushing of concrete, the compressive strength of the "strut" exhibits a strong size effect (Bažant 1997). This size effect, well evidenced by tests (Walraven and Lehwalter 1994; Tan and Cheng 2006), is yet to be incorporated into design codes, as well as into the usage of strut-and-tie model.

Stirrups or other shear reinforcement are known to significantly enhance the shear strength of deep beams, thanks to strengthening of the so-called compression strut. However, this enhancement is not unlimited and the concrete compression strut eventually fails by compression-shear crushing, which has been shown to exhibit size effect (Bažant 2005; Bažant and Xiang 1997). In the test series conducted by Walraven and Lehwalter (1994), a marked size effect is documented for geometrically similar deep beams with stirrups heavier than the minimum requirement.

The present study deals only with slender beams having minimum or heavier stirrups. Compared with the deep beams, the failure mechanism of slender beam is more complicated and less understood (e.g., ACI-ASCE 1998). Although fracture mechanics of a modified classical strut-and-tie model can explain the size effect in concrete beams with stirrups if the energy release caused by the growth of a compression crushing band in the compression strut is taken into account (Bažant 1997), the inclination and the 
effective cross section of the strut cannot be determined easily, which takes away the usefulness for prediction. The experimental, as well as computational, evidence (Frosch 2000; Angelakos et al. 2001; Tompos and Frosch 2002; Bažant and Yu 2005b) shows that the compressive resultant in the concrete ligament between the diagonal crack tip and the top face in slender beams has a steeper slope than what is assumed in the simple, classical version of the strut-and-tie model (Lampert and Thürlimann 1969).

The uncertainty of the correct slope and cross section area of the compression strut in slender beams under shear is compounded by the inclusion of shear reinforcement. It makes it difficult to obtain simple formulas for the stress redistribution and fracture energy release during crack propagation. However, it has been established (Bažant and Yu 2005a, b) that the shear failure of slender beams is triggered by compression-shear crushing of concrete in the ligament above the tip of the main diagonal crack. The size effect caused by concrete crushing could be avoided only if the concrete above this tip were provided with a strong triaxially confining reinforcement such as a spiral. But such design measures seem too laborious and expensive. So the size effect must be taken into account.

Some researchers discussed the size effect on the basis of average shear stress $v_{i}$ at the initiation of the primary shear crack (Tompos and Frosch 2002). However, what is needed for design is the average shear stress $v_{n}$ at maximum load, whose correlation to $v_{i}$ is unknown and certainly not unique. Therefore, what must be tested is the maximum loads of beams of significantly different sizes. Because of inevitable scatter, the beams should ideally have the size range $>8: 1$. The beams should be geometrically scaled, so as to separate the size effect from the effects of changing geometry (e.g., changing $a / d$, longitudinal steel ratio $\rho_{w}$, etc.). Changes of geometry from one size to the next would obfuscate the evaluation.

Only two relevant series of tests, with an almost geometrical scaling but a relatively narrow size range, could be found in the literature:

1. Tests of normal concrete beams by Bhal (1968) in which the size range was slightly less than $4: 1$. The stirrup ratio was $0.15 \%$, which was higher than the minimum required by ACI 318 (ACI 2008). The shear span ratio was $a / d=3$.

2. Tests of high strength concrete beams by Kong and Rangan (1998), in which the size range was only 3:1. The stirrup ratio was $0.157 \%$, higher than the required minimum. The shear span ratio was $a / d=2.4$. Although this value is slightly less than 2.5, the code limit for slender beams, the beams failed by typical diagonal shear, and so they may generally be treated as slender beams (Zararis 2003).

Plots in the logarithmic scales (Fig. 1) show that, in both Bhal's and Kong and Rangan's tests, the shear strength markedly (a)

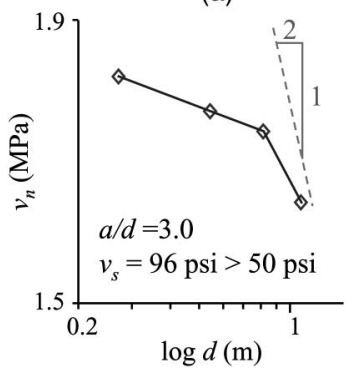

(b)

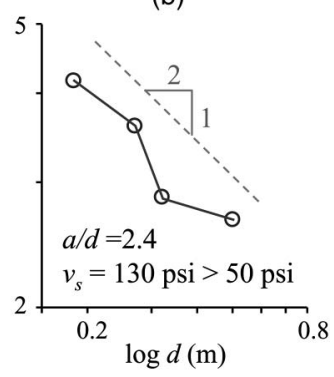

Fig. 1. Size effect tests of slender beams with stirrups; (a) concrete beam with $a / d=3$ by Bhal (1968); (c) concrete beam with $a / d=$ 2.4 by Kong and Rangan (1998) decreases as the beam depth increases. The asymptotic size effect trend of slope $-1 / 2$, derived on the basis of fracture mechanics, does not disagree with these test results. Nonlinear least-square regression based on Levenberg-Marquardt algorithm has been used to obtain the optimum values of the size effect law parameters [Eq. (2)]. It is found that $v_{0}=1.88 \mathrm{MPa}$ (273 psi) and $d_{0}=$ $3893 \mathrm{~mm}\left(153\right.$ in.) for Bhal's tests, and $v_{0}=4.32 \mathrm{MPa}$ (626 psi) and $d_{0}=324 \mathrm{~mm}$ (12.8 in.) for Kong and Rangan's tests. No comparison tests of identical beams without stirrups were made, and so the influence of reinforcement on the size effect, and particularly on the transitional size $d_{0}$, cannot be appraised from these tests directly.

Based on the ACI 445F database of 398 data points (Reineck et al. 2003), an empirical formula for estimating $d_{0}$ of slender beams without stirrups has been developed (Bažant and $\mathrm{Yu}$ 2005b). In the units of psi and inch, it reads

$$
\begin{aligned}
& d_{0}=\kappa f_{c}^{\prime-2 / 3} \text { where } \kappa=3800 \sqrt{d_{a}} \text { if } d_{a} \text { is known, } \\
& \kappa=3300 \text { if not }
\end{aligned}
$$

in which $d_{a}$ is the maximum aggregate size. With $d_{a}=30 \mathrm{~mm}$ (1.18 in.) and $f_{c}^{\prime}=26 \mathrm{MPa}(3769 \mathrm{psi})$, Eq. (3) gives $d_{0}=$ $433 \mathrm{~mm}$ (17 in.) for Bhal's tests. For Kong and Rangan's tests with $d_{a}=7 \mathrm{~mm}$ (0.3 in.) and $f_{c}^{\prime}=87.3 \mathrm{MPa}$ (12671 psi), Eq. (3) gives $d_{0} \approx 93 \mathrm{~mm}$ (3.7 in.).

Thus, it appears that, in Bhal's tests, the effect of shear reinforcement is to push the onset of size effect to larger sizes, raising the transitional size $d_{0}$ by almost one order of magnitude. In Kong and Rangan's tests, the stirrups also help to mitigate the size effect by increasing $d_{0}$ but to a lesser extent. The reason may be that Kong and Rangan's beams were made of high strength concrete, which is more brittle than normal concrete.

A similar effect of stirrups is found for deep beams. Walraven and Lehwalter (1994) conducted three series of tests of deep beams, which were scaled almost geometrically. The shape was the same for each depth $d$ and all the three series, but one series had no stirrups, and the other two had stirrups heavier than the minimum required. Data fitting showed that $d_{0}$ is $117 \mathrm{~mm}$ (4.6 in.) and $143 \mathrm{~mm}$ (5.6 in.) for the two series with stirrups, and $d_{0}=15.5 \mathrm{~mm}(0.6 \mathrm{in}$.) for the series without stirrups, which is about 10 times smaller.

\section{Finite-Element Fracture Analysis}

\section{Size Effect Calibrated by Existing Test Data}

Recently, another series of size effect tests of RC beams was conducted at the University of Toronto (Podgorniak-Stanik 1998; Angelakos et al. 2001; Lubell et al. 2004). First, the size effect was tested on slender beams without stirrups, using geometrically similar specimens with depths $d$ ranging from 0.11 to $1.89 \mathrm{~m}$ (4.3 to $74.4 \mathrm{in}$.). Then one beam identical to the largest one, but strengthened by minimum stirrups with $\rho_{s}=0.08 \%$, was tested for the sake of comparison. For the beam without stirrups, the measured shear strength was about $50 \%$ lower than the prediction on the basis of ACI 318 (ACI 2008); but for the beam with stirrups a significant improvement was observed, the strength was just above the ACI code requirement.

One test, of course, does not validate the safety of design. Similar to a recent statistical analysis (Bažant and Yu 2006, 2007, 2009), one could show that a test at the limit of code requirement gives a failure probability orders of magnitude higher than $10^{-6}$, which is unacceptable for structural design. Nonetheless, this result was perceived by many researchers as an experimental evidence 
that the size effect in large beams under shear can be eliminated by stirrups (Lubell et al. 2004).

This perception is not sound. The unsoundness will be confirmed by deterministic computations on the basis of nonlinear fracture mechanics. A finite-element model that was previously verified by fitting the results for beams without stirrups (Bažant et al. 2007) has now been enhanced in a well-known standard way to include the effect of stirrups. This model has been calibrated so as to fit the data on the single existing test of a large beam with stirrups, recently conducted at the University of Toronto. After such calibration, this model is now used to examine the size effect in geometrically similar beams with stirrups.

It must be emphasized that the failure loads for different sizes cannot be obtained by direct application of popular commercial finite-element codes on the basis of critical stress or strain. These codes might give correct results for small structures with quasiductile behavior but cannot capture brittle behavior with its size effect. To avoid spurious mesh sensitivity, to prevent excessive localization of cracking damage, to ensure correct energy dissipation by cracking zones and to capture the size effect, one must use either the nonlocal or the crack-band approach (Bažant and Jirásek 2002). The latter is simpler and is implemented in the commercial code ATENA (2005), which is adopted here (Bažant and Oh 1983; Bažant and Planas 1998).

The beam geometry in these computer simulations is the same as in the Toronto tests. Computations are run for scaled geometrically similar beams of depths $0.47 \mathrm{~m}$ (18.6 in.) and $1.89 \mathrm{~m}$ (74.4 in.), which is the size of the Toronto tests, $3.78 \mathrm{~m}$ (148.8 in.) and $7.56 \mathrm{~m}$ (297.6 in.). The width of all the beams is $b=300 \mathrm{~mm}$ (11.8 in.), i.e., the beams are similar in two dimensions. The stirrups and longitudinal bars are modeled by two-node bar elements and are assumed not to slip at the finite-element nodes (this assumption was verified by checking that, if the bars are detached from some nodes to allow free bond slip, the size effect would get intensified only slightly).

In all the simulations, the constitutive model for concrete is microplane model M4 (Bažant et al. 2000; Caner and Bažant 2000) with concrete strength $f_{c}^{\prime}=33.6 \mathrm{MPa}$ (4,870 psi), elastic modulus $E_{c}=28 \mathrm{GPa}(4,060 \mathrm{ksi})$ and Poisson's ratio $\nu=0.18$; and the steel bars are modeled by a simple bilinear law with elastic modulus $E_{s}=210 \mathrm{GPa}(30,450 \mathrm{ksi})$, yield strength $f_{y t}=470 \mathrm{MPa}$ $(67.9 \mathrm{ksi})$ for stirrups and $f_{y t}=457 \mathrm{MPa}(66.3 \mathrm{ksi})$ for tensile reinforcement. The mesh and the computed cracking pattern at maximum load are shown for the Toronto size beam in Fig. 2(a).

The plots of the simulated strength versus the dimensionless deflection (i.e., the midspan deflection divided by the span) are presented in Fig. 2(b), for all the sizes. In Fig. 2(b), the diamonds represent the measured results for $1.89 \mathrm{~m}$ (74.4 in.) deep beam with minimum stirrups, and the circles the results for the same beam without stirrups.

Unfortunately, the numerical simulations of these beams showed that not all of them fail in shear. Instead, the failure mode is changing as the size increases. As suggested by the computed load-deflection diagrams having a long plateau before the onset of softening, the beams fail in flexure for sizes $d=0.47$ and $1.89 \mathrm{~m}$ (18.6 and 74.4 in.). The simulations indicate that, at peak load, the flexural reinforcement at the bottom of these two beams is yielding, which is a flexural failure.

The diagram for $d=1.89 \mathrm{~m}$ (74.4 in.), the size tested in Toronto, shows a peak load of $V_{n}=0.63 \mathrm{MN}$ (142 kips). This agrees well with the value recorded in the Toronto test, which is $V_{n}^{\text {test }}=0.65 \mathrm{MN}$ (146 kips) and is close to the shear force corresponding to the flexural load capacity calculated from the design code. The yield plateau observed in the Toronto test is also well (a)
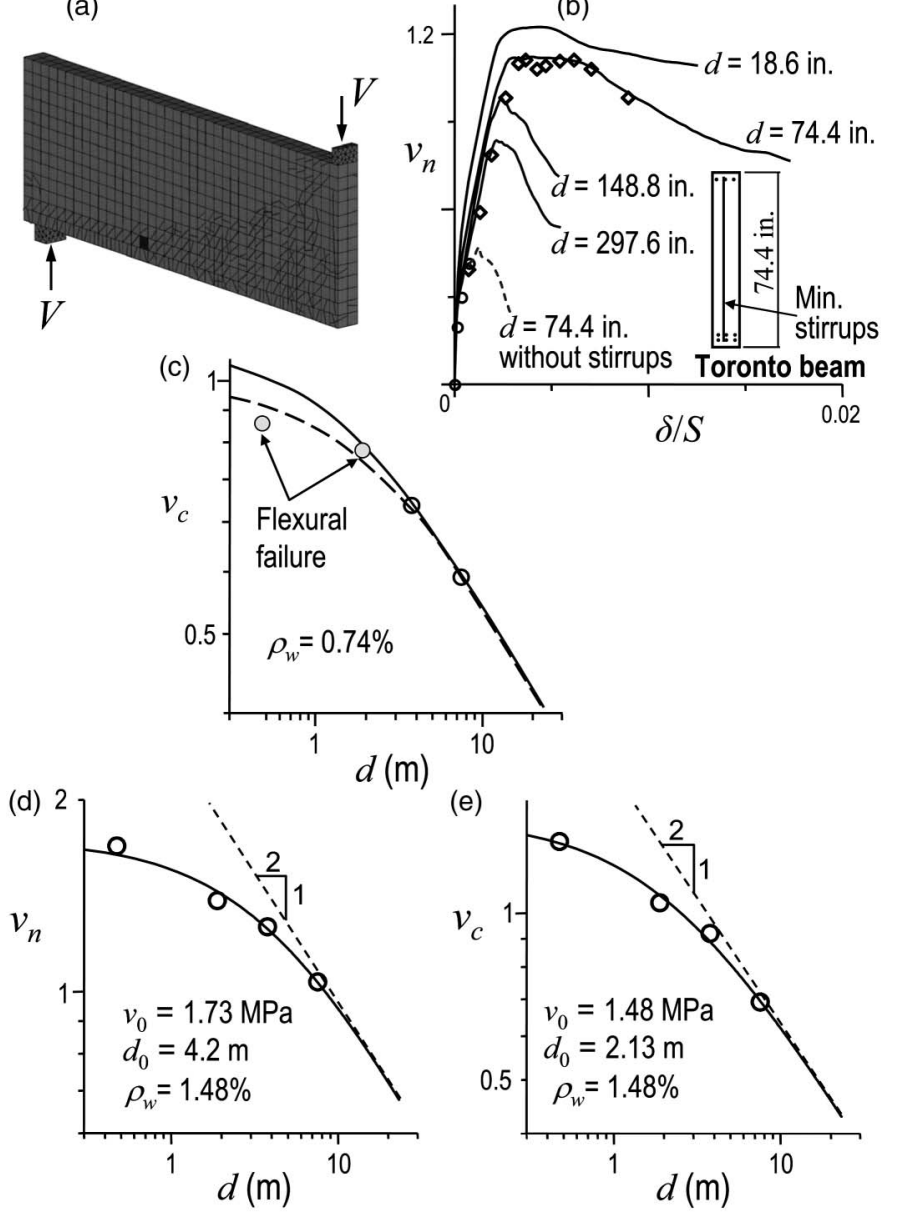

Fig. 2. Computational simulations of Toronto beam with minimum stirrups: (a) mesh and cracking pattern at failure; (b) load-deflection curves generated by simulations; (c) size effect fitting of the shear strength; (d) (e) size effect fitting of the shear strength after doubling $\rho_{w}$

reproduced by the simulation; see the diamond points in Fig. 2(b) measured in the test. The same close agreement between the test and the simulation is also obtained for the beam without stirrups. This corroborates the effectiveness of the microplane model and crack-band model to simulate concrete fracture under shear loading.

By contrast, the simulations for the beams of sizes $d=3.78$ and $7.56 \mathrm{~m}$ (148.8 and 297.6 in.) show shear failure. At maximum load, the stress in the flexural reinforcement in both of these beams is still far below the yield strength. Also, the yield plateau disappears and the load descends steeply right after the peak.

Fig. 2(c) shows the size effect on shear strength $v_{c}$ in the bilogarithmic scale. In the size range from $d=0.47$ to $1.89 \mathrm{~m}$ (18.6 to $74.4 \mathrm{in}$.), the size effect is seen to be very weak (a drop of less than $7 \%$ ). This is no surprise since the beams fail by flexure. However, for the larger sizes from $d=1.89$ to $7.56 \mathrm{~m}$ (74.4 to $297.6 \mathrm{in}$.), at which the beams fail by shear, the size effect is strong (representing a $35 \%$ drop).

Fitting the measured $v_{c}$ for all the sizes by the size effect law [Eq. (2)], one obtains $d_{0}=2,400 \mathrm{~mm}$ (94.5 in.). However, the use of size effect law for this particular data set is unjustified because of the flexural failure of the smaller beams. Nevertheless, the reason that the two smaller beams failed by flexure is that their shear strength values were higher. This implies that the size effect for shear is stronger than what is seen in Fig. 2(c) and that 
the correct transitional size $d_{0}$ for size effect in shear is $<2,400 \mathrm{~mm}$ ( $<94.5 \mathrm{in}$.).

To get complete information on the size effect in shear, all the beams must fail in shear. This can be achieved by doubling the flexural reinforcement ratio for all the beams. Figs. 2(d) and 2(e) presents a plot of the shear strength computed in the same way when the flexural reinforcement ratio is doubled to $1.48 \%$. Fig. 2(d) shows the dependence of the total beam shear strength $v_{n}=$ $V_{n} / b_{w} d$ on the beam depth $d$, and Fig. 2(e) shows the same for the portion of shear strength $v_{c}=V_{c} / b_{w} d$ contributed by concrete ( $V_{c}=V_{n}-V_{s}, V_{s}=A_{v} f_{y t} d / s ; A_{v}, s=$ stirrup area and spacing).

Compared to the concrete beams without stirrups tested at the same laboratory with the same concrete, the transitional size $d_{0}$ shown in Fig. 2(e) gets greatly increased-from $274 \mathrm{~mm}$ (10.8 in.) to $2,100 \mathrm{~mm}$ (82.7 in.). Nevertheless, despite a much larger $d_{0}$, these plots still display a strong size effect for very large sizes. Thus, it may now be clearly recognized that the effect of stirrups is not to eliminate the size effect but to push it to much larger sizes.

The simulation results show that a $50 \%$ reduction of shear strength would happen if the depths of the Toronto beams ranged from 0.47 to $7.56 \mathrm{~m}$ (18.6 to $297.6 \mathrm{in}$.), which is still in the practical range of interest. When plotted in the logarithmic scale, the asymptotic slope of $-1 / 2$ is seen to remain.

\section{Discussion of Numerical Simulations}

For slender beams, computational simulations show that the failure of concrete beams without stirrups is caused by the compressionshear crushing of concrete in the ligament above the diagonal crack tip (Bažant and Yu 2005a, b). Such crushing is generally accepted as the cause of shear failure in deep beams (Walraven and Lehwalter 1994; Tan and Lu 1999; Tan and Cheng 2006).
When the stirrups are placed into slender concrete beams, the crack propagation path changes and the development of a compressive strut becomes more complicated. This is exemplified by the variability of the slope of the inclined crack in the tests by other researchers (Frosch 2000; Tompos and Frosch 2002). However, the stirrups cannot provide the confinement necessary to prevent compression-shear crushing of concrete in the ligament above the diagonal crack tip. This insufficiency of stirrups is confirmed by the present calculations of the compressive stress in the ligament. For the beams with minimum stirrups and depths $d=$ 3.78 and $7.56 \mathrm{~m}$ (148.8 and $297.6 \mathrm{in}$.), the simulations show that, at the peak load, the maximum principal compressive stress within the ligament between the diagonal crack tip and the top face approximately equals the compressive strength $f_{c}^{\prime}$ of concrete [see Fig. 3(a)].

The computations help to understand the strength reduction. In large beams, unlike the small ones, the inclined compressive stresses transmitted across the ligament localize. The width of the stress localization zone is essentially constant and thus represents in larger beams a smaller portion of the ligament. During loading, the zone in which the compressive stress reaches strength limit $f_{c}^{\prime}$ travels across the ligament. At some points, $f_{c}^{\prime}$ is reached before peak load, at other points after the peak load [this behavior is similar to beams without stirrups; see Fig. 3(b)].

Thus, in contrast to small beams, the compressive strength of concrete is in large beams prevented from being mobilized at all points of the ligament simultaneously. This fact intuitively explains the size effect and explains why the plastic limit analysis does not apply.

As for the stresses transmitted by aggregate interlock across the diagonal crack, simulations show them to be important only for the initiation of diagonal crack long before the maximum load is (a)

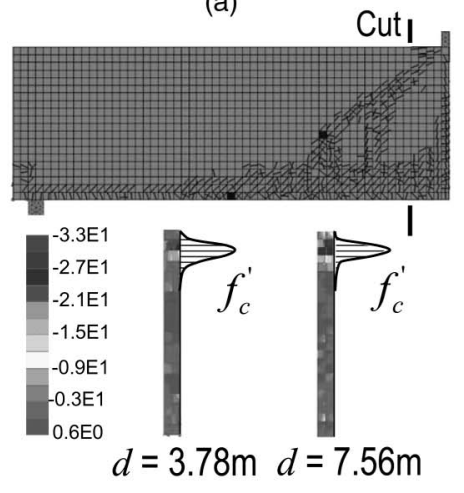

(c)

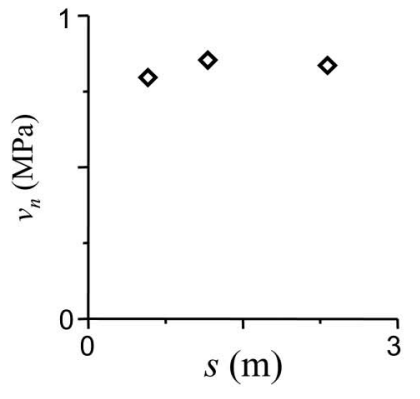

(d)

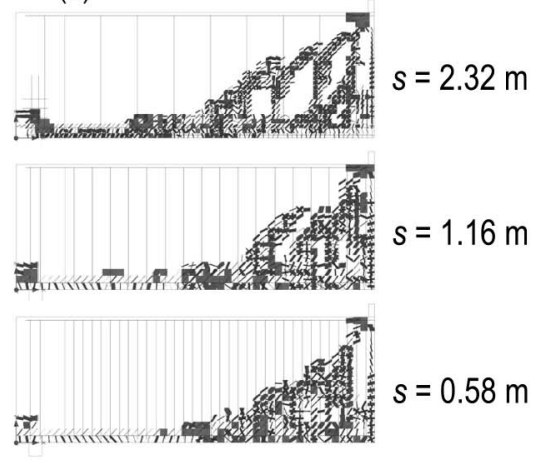

(e)

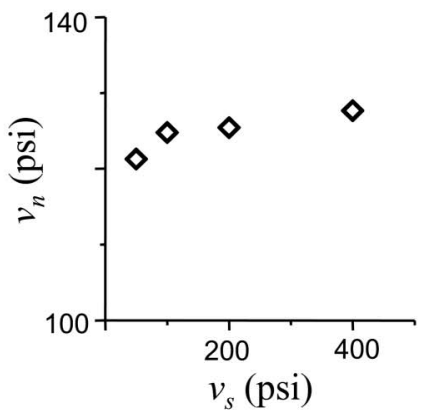

Fig. 3. (a) Compressive strength distribution in the concrete above the main diagonal crack for $d=3.78 \mathrm{~m}$ (148.8 in.) and $7.56 \mathrm{~m}$ (297.6 in.); (b) profile of compressive stress along uncracked ligament; (c) effect of spacing $s$ on the shear strength; (d) effect of spacing $s$ on the crack pattern; (e) effect of shear reinforcement $v_{s}$ on shear strength 
reached. At maximum load, the vertical resultant of these stresses contributes in large beams (e.g., $d=6 \mathrm{~m}$ or 236.2 in.) only about $5 \%$ of the total shear force.

To separate the size effect from other influences, the present simulations adhere to geometric similarity of beams scrupulously, through the entire size range. This leads to stirrup spacing $s=$ $2.32 \mathrm{~m}$ (91.3 in.) for the beam of depth $d=7.56 \mathrm{~m}$ (297.6 in.). This spacing exceeds the maximum spacing allowed by the current design codes (ACI 2008, 11.4.5.1). According to the code, the maximum stirrup spacing must be $s<610 \mathrm{~mm}$ (24 in.), regardless of the beam depth. Hence, did the excessive stirrup spacing enhance the size effect?

To answer this question, two more beams with the same stirrup ratio $(0.08 \%)$ and the same depth $d=7.56 \mathrm{~m}$ (297.6 in.) have been simulated in the same way for stirrup spacings $s=0.58 \mathrm{~m}$ (22.8 in.), which satisfies the requirement of ACI code, and $1.16 \mathrm{~m}$ (45.6 in). The results show that the changes of the total shear strength $v_{n}$ caused by these changes of stirrup spacing are within $6 \%$ [see Fig. 3(c)]. So, the influence of stirrup spacing on size effect is not too important.

The low influence of stirrup spacing is corroborated by the experiments of Tompos and Frosch (2002). They loaded to failure two $851 \mathrm{~mm}$ (33.5 in.) deep beams that had the same geometry, same concrete mixture and strength, same steel ratio and same stirrup ratio but different stirrup spacings $s=165 \mathrm{~mm}(6.5 \mathrm{in}$.) and $s=371 \mathrm{~mm}$ (14.6 in.). The total shear strength $v_{n}$ of the beam with denser stirrups was only $5 \%$ lower, which is within the range of random scatter and thus not significant. So, the spacing does not play an important role in the shear strength $v_{n}$. This conclusion agrees with the computer simulations.

The tests of Tompos and Frosch (2002) nevertheless revealed that an increase of stirrup spacing makes the overall inclination of the main diagonal shear crack steeper. This effect of stirrup spacing is further captured by the computer simulations [see Fig. 3(d)].

The effect of stirrup ratio $\rho_{s}$ on the shear strength has also been investigated. Generally, increasing $\rho_{s}$ will improve the total shear strength $v_{n}$, although it is well recognized that the linear relation in Eq. (1) is oversimplified and cannot realistically represent the interaction between concrete and stirrups. Kong and Rangan conducted in 1998 three relevant test series on high strength concrete beams. The results recorded from beams with $a / d=2.5$ under four-point bending are scattered and show no systematic relation between the stirrup ratio $\rho_{s}$ and the shear strength $v_{n}$. On the other hand, the results obtained from beams with $a / d=3.3$ under threepoint bending are consistent and document a clear trend. With $\rho_{s}$ varying from 0.1 to $0.26 \%, v_{n}$ increases from $2.95 \mathrm{MPa}$ (428 psi) to 4.22 $\mathrm{MPa}(611 \mathrm{psi})$, which is accompanied by a decrease of the slope of the $v_{n}\left(\rho_{s}\right)$ curve.

It has been checked that this trend is also captured numerically. Simulations for beams with $d=7.56 \mathrm{~m}$ (297.6 in.) are carried out for stirrups of $v_{s}=0.34,0.69,1.38$, and $2.76 \mathrm{MPa}(50,100,200$, and $400 \mathrm{psi}$ ), which all satisfy the condition $v_{s} \leq 8 \sqrt{f_{c}^{\prime}}$ (psi) required by the ACI code. The same stirrup spacings, $s=2.32 \mathrm{~m}$ (91.3 in.), are chosen for all the beams since the influence of $s$ has already been shown to be very small.

As seen from Fig. 3(e), $v_{n}$ increases when heavier stirrups are used. However, the increase of $v_{n}$ is quite mild and levels off after $v_{n}$ reaches $0.69 \mathrm{MPa}$ (100 psi). This noteworthy phenomenon is clarified by the numerical observation that, at maximum load, the stress in the stirrups that cross the main diagonal crack decreases as they become heavier. Light stirrups, with $v_{s}=0.34$ and $0.69 \mathrm{MPa}(50$ and $100 \mathrm{psi}$ ), reach at maximum load their yield strength. But heavier stirrups reach their yield strength only after the peak load of the beam, i.e., their yield strength cannot be mobilized at maximum load. For $v_{s}=2.76 \mathrm{MPa}$ (400 psi), the stress in stirrups at maximum load drops as low as one half of their yield strength.

So, as it is shown, the vertical confinement that can be contributed by stirrups to resist the compression-shear crushing of concrete is limited by a certain critical value, beyond which the shear failure occurs even if the stress in stirrups is much below their yield strength. Raising the stirrup ratio above the critical value contributes nothing to the shear strength. Calculations also show that this critical value of $v_{s}$ can be much smaller than $v_{s}=8 \sqrt{f_{c}^{\prime}}(\mathrm{psi})$, especially for large beams.

\section{Purely Statistical Analysis of Experimental Database}

\section{Safety Margins and Failure Probability When Size Effect Ignored}

Because many engineers accept only experimental evidence, let us focus in this section on the test data alone. In contrast to the beams without stirrups, no committee-endorsed database for beams with stirrups exists. Nevertheless, hundreds of tests have been reported in the literature over the past 50 years (Becq-Giraudon 2000; Zararis 2003; Russo et al. 2004). But most of them dealt with small beams and explored factors other than the size effect. Becq-Giraudon (2000) collected 295 tests, among which 182 tests were slender beams and the rest deep beams. Zararis (2003) set up a database with 174 beams, all of them slender, and Russo et al. (2004) collected data of 116 beams, all of them made with high strength concrete.

For the purpose of this study, a database of $234 v_{n}$ data has been collected from 26 papers. It is more comprehensive and gives a more detailed information than the aforementioned data sets (Leonhardt and Walther 1962; Bresler and Scordelis 1963, 1966; Krefeld and Thurston 1966; Bhal 1968; Rajagopalan and Ferguson 1968; Placas and Regan 1971; Swamy and Andriopoulos 1974; Mattock and Wang 1984; Mphonde and Frantz 1985; Elzanaty et al. 1986; Johnson and Ramirez 1989; Anderson and Ramirez 1989; Roller and Russell 1990; Sarzam and Al-Musawi 1992; Xie et al. 1994; McGormley et al. 1996; Yoon et al. 1996; Kong and Rangan 1998; Zararis and Papadakis 1999; Karayiannis and Chalioris 1999; Frosch 2000; Angelakos et al. 2001; Tompos and Frosch 2002; Lubell et al. 2004; Shah and Ahmad 2007; the database is downloadable at http://www.iti.northwester.edu). All the data are for slender beams under 3- or 4-point bending. For each test, the database gives the required mean strength of concrete $f_{c r}^{\prime}$, relative shear span $a / d$, longitudinal steel ratio $\rho_{w}$, stirrup steel ratio $\rho_{s}$, and except for 71 tests for which the information was missing, maximum aggregate size $d_{a}$. In this database, 183 data points satisfy the minimum stirrup requirement of ACI code, $v_{s} \geq \max \left(50,0.75 \sqrt{f_{c}^{\prime}}\right)$ psi, and only those can be used in the statistical analysis that follows.

Although, as shown in the preceding section, the stirrups in very large beams begin to yield only a long way into the postpeak softening, the need to make comparisons with Eq. (1) compels us to calculate from the database points a nominal value, $v_{c}=v_{n}-v_{s}$, as if the stirrups were always yielding at peak load. The database points are displayed in Fig. 4(a). The scatter is large and a downward size effect trend may barely be discerned. The logarithmic scale of $y=\ln v_{n}$ or $\ln v_{c}$ makes the data set approximately homoscedastic, i.e., achieves approximately uniform variance [Figs. 4(a) and 4(b)], which is required for meaningful regression statistics (Ang and Tang 1976). Note, however, that if the data were plotted in the linear scale of $v_{n}$ or $v_{c}$, they would be strongly heteroscedastic, which means that the linear scale is inappropriate. 

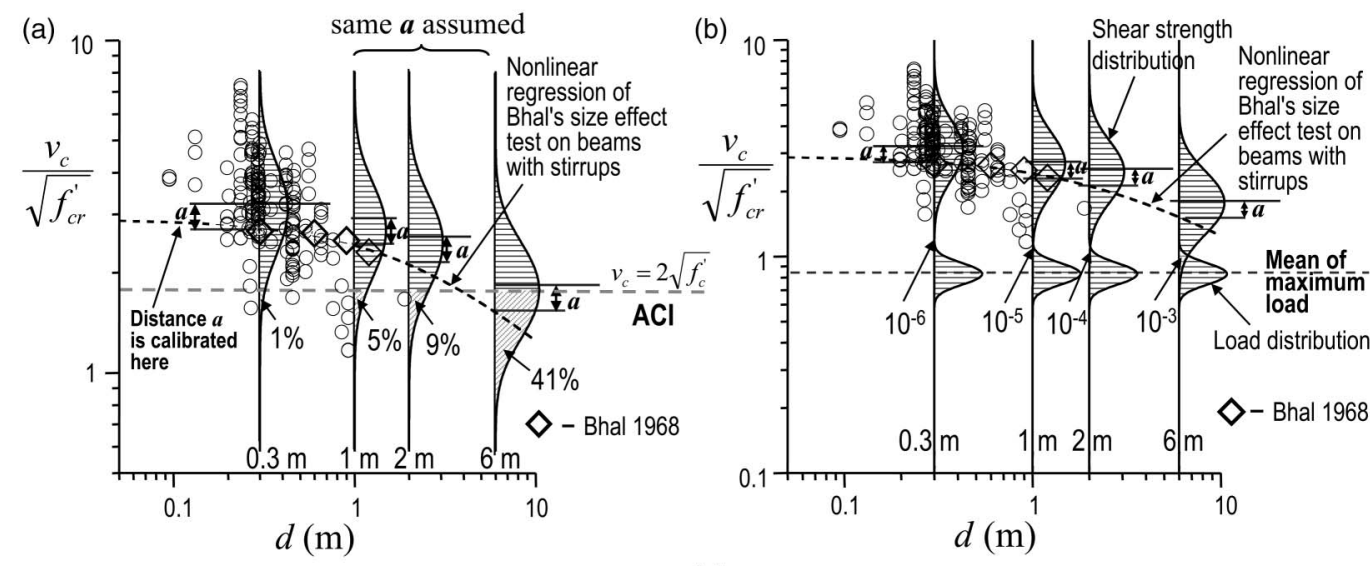

(c)
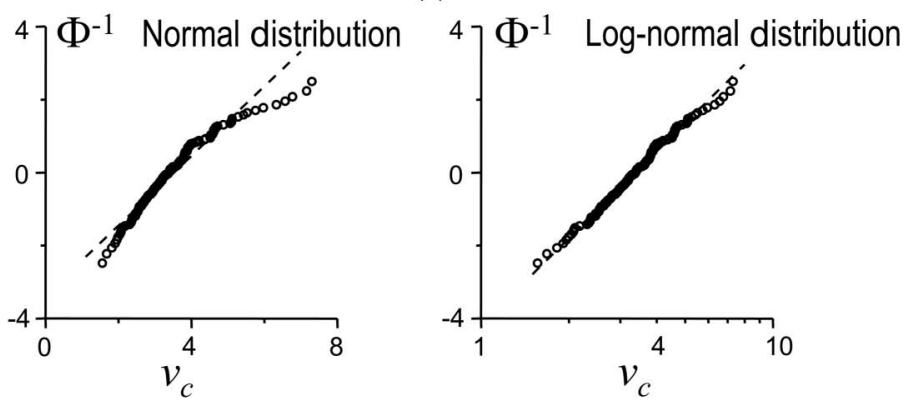

Fig. 4. (a) Distribution of concrete shear strength versus size of beam; (b) failure probability of shear beam versus size of beam; (c) cumulative histogram of data on normalized beam shear strength beams with $d \leq 500 \mathrm{~mm}$ (19.7 in.) plotted on both normal and log-normal probability paper, and their straight-line fit

Fig. 4(a) documents that shear reinforcement enhances the shear strength of beams significantly. With $f_{c r}^{\prime}$ (i.e., the required average compressive strength of concrete, which implies, for normal concretes, $f_{c}^{\prime} \approx \sqrt{0.7} f_{c r}^{\prime}$ in psi), the mean (normalized) total shear strength is $v_{n}=5.02 \sqrt{f_{c r}^{\prime}}$. This value considerably exceeds the size-independent shear strength $v_{c}=2 \sqrt{f_{c}^{\prime}}$ based on the ACI code equation 1 and is much greater than the mean shear strength $v_{c}=3.1 \sqrt{f_{c r}^{\prime}}$ obtained from the ACI 1962 database for beams without stirrups (Bažant et al. 2007).

However, this shear strength enhancement does not mean that the current building code would provide the necessary safety margin. For depth $d \leq 500 \mathrm{~mm}$ (19.7 in.), 6 beams among 155 failed at $v_{c}<2 \sqrt{f_{c r}^{\prime}}$. For $d>500 \mathrm{~mm}$ (19.7 in.), it gets worse; 8 beams among 28 failed at $v_{c}<2 \sqrt{f_{c r}^{\prime}}$, and it may be emphasized that some $1 \mathrm{~m}$ (39.4 in.) deep beams had shear strength as low as $v_{c} \approx 1.1 \sqrt{f_{c r}^{\prime}}$. Overall, about $30 \%$ of the large beams tested does not provide adequate safety margin if designed according to ACI code equation 1 . This fact cannot be ignored.

To calculate the safety margins, we may proceed similarly to a recent study of beams without stirrups (Bažant and Yu 2009). First, the probability distribution function (PDF) of beam strength cannot be obtained by population (or ensemble) statistics of the entire database because there is too much scatter (Bažant et al. 2007; Bažant and $\mathrm{Yu} 2007,2009)$. However, if we isolate the small-size range of the database for $d \leq 500 \mathrm{~mm}$ (19.7 in.), the data are still plentiful and the size effect trend is seen to be weak. So the data in this range can be treated as a statistical population. We plot a cumulative histogram of the $v_{c}$ values from the small-size range and do so in various types of probability papers to decide which PDF fits best; see Fig. 4(c), which shows that the cumulative histogram fits quite closely a straight line on the log-normal probability paper, much closer than it does on the normal probability paper. Similar to a recent study (Bažant and $\mathrm{Yu}$ 2009), this observation may be checked by the goodness-of-fit tests, e.g., the widely used K-S test (Chakravarti et al. 1967) and the chi-square test (Snedecor and Cochran 1989). Note the difference from the strength distribution for identical specimens with a single type of material, which cannot be log-normal (Bažant and Pang 2007) because what dominates the database scatter are the differences among various concretes, $f_{c}^{\prime}$, $a / d, \rho_{w}, \rho_{s}$, rather than the randomness of one concrete per se.

Fig. 4(b) shows the log-normal PDF of normalized strength $v_{c} / \sqrt{f_{c r}^{\prime}}$ positioned at the mean depth $\bar{d}=315 \mathrm{~mm}$ (12.4 in.) of the beams with stirrups in the small-size range. Its coefficient of variation $(\mathrm{CoV})$ is $\omega=0.30$ (and the parameters are $\lambda=1.22$ and $\zeta=0.29$ where $\lambda$ and $\zeta$ are the mean and standard deviation of the natural logarithm of the normalized strength). By using statistical distribution tables or programs, one finds from these parameters that the probability that small beams with $d \leq 500 \mathrm{~mm}$ (19.7 in.) would have $v_{c}<2 \sqrt{f_{c r}^{\prime}}$ is only $3.5 \%$. This small infringement on the code limit seems to be acceptable for design.

The question now is how to determine the PDF of $v_{c}$ of large beams with stirrups, for which the data are limited to one type of beam, whereas test data for many different concretes and different $f_{c}^{\prime}, a / d, \rho_{w}$, and $\rho_{s}$ are lacking. If such test data were available, the variation of these parameter would cause about the same relative changes in $v_{c}$. For this reason, and in similarity to the statistical analysis of beams without stirrups (Bažant and Yu 2009), we must expect that if many large beams for many different concretes and different $f_{c}^{\prime}, a / d, \rho_{w}$ and $\rho_{s}$ could be tested, the log-normal distribution of their $v_{c}$ would have the same shape in the log-scale, and particularly the same $\mathrm{CoV}$ as that for the small-size range, i.e., $\omega=0.30$.

Given the size independence of the shape of the log-normal pdf, the only further information needed is the location of the mean of 
the PDF of $v_{c}$ of large beams. To this end, the size effect data of Bhal (1968), represented by the diamond points in Figs. 4(a) and 4(b), may be used. The normalized mean shear strength $\bar{v}_{c} / \sqrt{f_{c r}^{\prime}}=$ 3.52 of the small-size beams is located above the $v_{c}$ value for the small beam of Bhal's series (with $d=300 \mathrm{~mm}=11.8$ in.). As seen in Figs. 4(a) and 4(b), the mean is shifted upward by $24 \%$, i.e., by distance $a=\log 1.24=0.093$. Because the concrete type, $f_{c}^{\prime}, a / d, \rho_{w}$, and $\rho_{s}$ were, in Bhal's series, kept nearly the same for all the beam sizes, the distance of upward shift (in the log-scale) of the PDF mean from the $v_{c}$ value measured by Bhal on his largest beam $(d=1.2 \mathrm{~m}=47.2 \mathrm{in}$. $)$ must be about the same and approximately equal to the upward shift $a$ for small beams. [There are some other subtle points in this kind of argument, e.g., the randomness of $a$, but they were already discussed before and were demonstrated to have a negligible effect on the final results (Bažant and Yu 2009).]

Similar to the study of RC beams without shear reinforcement (Bažant and Yu 2009), consider now beams with stirrups about $1 \mathrm{~m}$ (39.4 in.) deep. When the mean of the log-normal PDF is shifted up by distance $a$ from the size effect curve measured by Bhal (1968), one finds that the percentage of the tests of $0.9 \mathrm{~m}$ (35.4 in.) deep beams made with different concretes and different $f_{c}^{\prime}, a / d, \rho_{w}$, and $\rho_{s}$, would fall below the code limit $v_{c}=2 \sqrt{f_{c r}^{\prime}}$ is $5.7 \%$. For beams $1.2 \mathrm{~m}$ deep, which is the depth of the largest beam of Bhal, this percentage rises to $8.6 \%$. For deeper beams, the percentages are, of course, still larger (e.g., for $2 \mathrm{~m}$ deep, it would be $15.7 \%$, and $6 \mathrm{~m}$ deep, $55.1 \%$ ).

Similarly, one may further combine the beam strength distribution with the load distribution and calculate probability $P_{f}$ of failure. For the beams of Bhal's type, one gets $P_{f}=10^{-6}, 10^{-5}$, $10^{-4}$, and $10^{-3}$ for $d=0.3 \mathrm{~m}, 1,2$, and $6 \mathrm{~m}$, respectively [for the calculation procedure, see Bažant and Yu (2009)]. Note also that $10^{-6}$ is considered by reliability experts as the maximum tolerable (Melchers 1987; Duckett 2005) and the higher $P_{f}$ values as intolerable.

The foregoing arguments, which were deliberately based on the statistics of experimental data alone, suffice to show that the size effect on beams with stirrups must be taken into account in practice.

\section{Regression of Size Effect Data after Minimizing Statistical Bias}

There are two types of statistical bias in the compiled database: (1) a nonuniform distribution of secondary influencing factors; and (2) unequal numbers of data points in different size ranges. As illustrated in Figs. 4(a) and 4(b), most of the data points are crowded in the small-size range; $85 \%$ of the beams have a depth $d<0.5 \mathrm{~m}$ (19.7 in.), $99 \%$ have $d<1.2 \mathrm{~m}$ (47.2 in.), and no beam has a depth $d>1.89 \mathrm{~m}$ (74.4 in.). If statistical regression with uniform weights were conducted, the statistics would be dominated by small-size beams for which the size effect is very weak, and the beams with $d>1.2 \mathrm{~m}$ would be irrelevant. At the same time, the size effect on shear strength is obscured by enormous scatter in the database [Figs. 4(a) and 4(b)], which stems mainly from the variability of secondary, although significant, influencing factors, such as $f_{c}^{\prime}, a / d, \rho_{w}, \rho_{s}, d_{a}$, concrete composition and curing. Both types of bias must be minimized.

To this end, we emulate a recent study of Bažant and Yu (2007, 2008), subdividing the size range into four intervals of equal widths in $\log d$ (Fig. 5), which range from 0.15 to $0.3 \mathrm{~m}$ (6 to $12 \mathrm{in}$.), from 0.3 to $0.6 \mathrm{~m}$ (12 to $24 \mathrm{in}$.), from 0.6 to $1.2 \mathrm{~m}$ ( 24 to $48 \mathrm{in}$.), and from 1.2 to $2.4 \mathrm{~m}$ (48 to 96 in.). If the entire database were to be obtained in one centrally directed testing program, a sound statistical design of experiment would have dictated choosing the same number of tests in each size interval and maintaining within each size interval

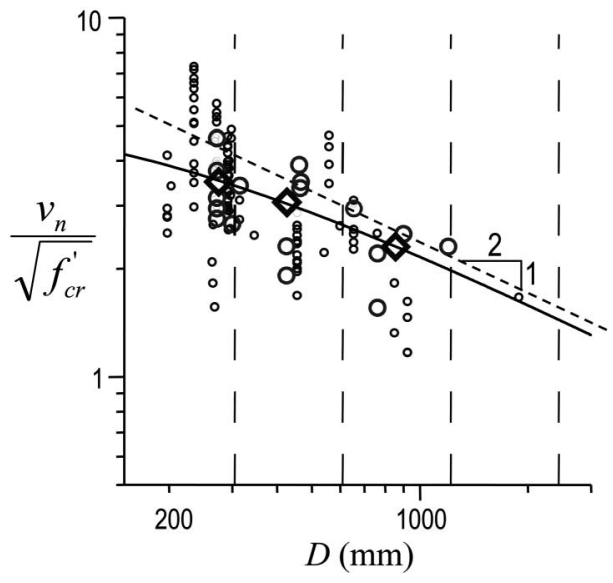

Fig. 5. Statistical regression of centroids after restricting the secondary influencing parameters in size intervals

the same mean and the same CoV of the secondary influencing parameters $a / d, \rho_{w}, \rho_{s}$, and $f_{c}^{\prime}$. To approach this ideal situation as closely as possible, the database must be filtered.

In the existing database, the means of $\rho_{w}, a / d, \rho_{s}$, and $d_{a}$ vary significantly from one interval to the next, and so the trend of the entire database in the plot of $v_{n}$ versus $d$ represents some combination of size effect with the effects of $\rho_{w}, a / d, \rho_{s}$, and $d_{a}$, rather than the size effect alone. To identify the size effect from experiments in a purely statistical way, we must filter the database so as to retain in each size interval (Fig. 5) only those data that give about the same mean of parameters $\rho_{w}, a / d, \rho_{s}$, and $d_{a}$.

As for the stirrup spacing $s$, we cannot enforce the same mean because there would not be sufficient number of data left in the intervals after filtering. But this is not a serious problem because the effect of spacing $s$ is weak. For the same reason, we cannot filter the database to achieve the same $f_{c}^{\prime}$ in each interval. But the influence of $f_{c}^{\prime}$ may be largely suppressed by using $v_{c} / \sqrt{f_{c}^{\prime}}$ as the ordinate because it is generally agreed that $v_{c}$ is approximately proportional to $\sqrt{f_{c}^{\prime}}$.

Compared with the previous study of beams without stirrups, an additional problem arises in plotting $v_{n}=v_{c}+v_{s}$ because, in determining $v_{s}$, it is not known whether the stirrups yield before or after the maximum load (this question could only be answered by fracture-based finite-element simulation of each test in the database). The best that can be done with the information available is to use the $v_{s}$ value for yielding stirrups and plot $v_{n} / \sqrt{f_{c}^{\prime}}=v_{c} / \sqrt{f_{c}^{\prime}}+v_{s} / \sqrt{f_{c}^{\prime}}$. The implied reduction of $v_{s}$ for higher $f_{c}^{\prime}$ happens to partially compensate for the fact that if the concrete strength in large beams is increased, the stirrups are less likely to yield at maximum load.

To avoid human bias, the data must be filtered from the database by a computer algorithm with mathematical rules. The algorithm [which need not be described here as it was presented in detail in Bažant and Yu (2008)] removes progressively from each interval the data points from the upper and lower margins so as to minimize the sum of squared differences of secondary parameters $\rho_{w}, a / d, \rho_{s}$, and $d_{a}$ from their desired means $\bar{\rho}_{w}, \overline{a / d}, \bar{\rho}_{s}$, and $\bar{d}_{a}$. The algorithm is run for many possible value of the means until a data set with minimum variation in all the secondary parameters among the intervals is found, while a sufficient number of data points is retained.

In the compiled database of 183 data points which satisfy the minimum stirrup requirement, there are 51 tests in which the concrete aggregate size $d_{a}$ was not reported. In view of the influence of $d_{a}$ on $v_{c}$, which has already been documented for beams without 
stirrups (Bažant and Yu 2005b; Bažant et al. 2007), these 51 data points have been deleted. The remaining 132 data points are divided into the aforementioned four size intervals (Fig. 5). As seen, there is only one test falling into the size range from 1.2 to $2.4 \mathrm{~m}$ (48 to $96 \mathrm{in}$.). This test, made at the University of Toronto (Lubell et al. 2004), has a steel ratio of $\rho_{w}=0.74 \%$, which is so low that no test of similar $\rho_{w}$ is found in the other size intervals. Therefore, we can only consider the size range from 0.3 to $1.2 \mathrm{~m}$ (6 to 48 in.), subdivided into three intervals.

If the parameter ranges are restricted by the filtering algorithm (Bažant and Yu 2007, 2008), 9, 6, and 5 data points remain in the first, second, and third size intervals, respectively. (Ideally, of course, the number of data in each interval should be the same, and the fact that it is not shows that complete elimination of statistical bias is impossible; nevertheless for obtaining the means, even 3 data points would suffice.) For the restricted parameter ranges, the mean values of $\rho_{w}$ are, respectively, 1.93, 1.90, and $1.91 \%$; the mean values of $a / d$ are $3.3,3.6$, and 3.1 ; the mean values of $v_{s}$ are $0.59,0.61$, and $0.64 \mathrm{MPa}(85,88,93 \mathrm{psi})$, and the mean values of $d_{a}$ are 20,19 , and $21 \mathrm{~mm}(0.79,0.75$, and 0.83 in.). This filtering yields data samples with minimum bias in terms of $\rho_{w}, a / d, \rho_{s}$, and $d_{a}$.

The data centroids for each interval are plotted as the diamond points in the plot of $\log \left(v_{c} / \sqrt{f_{c r}^{\prime}}\right)$ versus $\log d$ (Fig. 5). Despite enormous scatter in the database, the trend of these centroids is quite systematic. The trend shows a negative curvature and the last 2 points conform to the asymptotic slope of $-1 / 2$.

Only statistical analysis of test data, with no mechanics, no finite-element analysis and no human intervention, has been used to get this result.

Assuming each centroid in Fig. 5 to have the same weight suppresses the second kind of bias because of unequal numbers of data in the individual intervals. Optimum fitting of the centroids is then used to obtain the classical size effect law [Eq. (2)]; see the solid curve in Fig. 5, approaching an asymptote of slope $-1 / 2$. The CoV of the errors of the fit is $\omega=1.0 \%$, which is very small.

\section{Conclusions}

1. Although stirrups mitigate the size effect on the shear strength of RC beams, they cannot suppress it completely, regardless of the stirrup ratio.

2. The stirrups, whether minimum or heavier, do not change the shape of the size effect curve but push it, in the bilogarithmic scale, into larger sizes, increasing the transitional size $d_{0}$ by almost one order of magnitude. Thus the size effect of shear strength is mitigated in the small-size range (up to about $1 \mathrm{~m}$ or 39.4 in. beam depth), but remains the same in the large size range.

3. Computational simulations on the basis of a realistic damage constitutive model and the crack-band approach of nonlinear fracture mechanics show that RC beams with or without stirrups fail by compression-shear crushing of the concrete between the diagonal crack tip and the top face.

4. The simulations also imply that the effect of shear reinforcement ratio on the shear strength is not linear. Large enough beams reach their maximum load before the stirrups yield, and then further strengthening of the shear reinforcement will not improve the shear strength of the beam.

5. Although the spacing of stirrups significantly affects the inclination of the diagonal shear crack, it has a negligible effect on the shear strength of beam.
6. The probability distribution of beam strength identified from the database shows that about $3.5 \%$ of beams of depth $d<$ $0.5 \mathrm{~m}$ have a strength lower than required by the code. For $d=1,2,6 \mathrm{~m}$, this percentages rises to $6.5,15.7$, and $55.1 \%$, respectively, if the size effect is ignored. The corresponding failure probabilities for $d<0.5,1,2$, and $6 \mathrm{~m}$ are $10^{-6}, 10^{-5}, 10^{-4}$, and $10^{-3}$, respectively, if the size effect is ignored. The first probability is acceptable, but the others are not.

7. The size effect in the database is contaminated by the secondary influences of the shear span ratio and longitudinal and stirrup steel ratios because the means of these parameters within subsequent intervals of size vary significantly with increasing size. Filtering the database can make these means nearly size-independent. Then the data centroids in the subsequent intervals exhibit a clear size effect trend, which agrees with the theoretical size effect.

\section{Acknowledgments}

This study was motivated by the goals of ACI Committee 446, Fracture Mechanics, and was supported by the Department of Transportation through the Infrastructure Institute of Northwestern University, under Grant No. 60020778.

\section{References}

ACI Committee 326. (1962). "Shear and diagonal tension." J. Am. Concr. Inst., 59, 1-30, (Jan.), 277-344 (Feb.), 352-396 (March).

ACI Committee 445. (1998). "Recent approaches to shear design of structural concrete." J. Struct. Eng., 124(12), 1375-1417.

ACI Committee 318. (2008). Building code requirements for structural concrete (ACI 318-08) and commentary (ACI 318R-08), American Concrete Institute, Farmington Hills, MI, 430.

Anderson, N. S., and Ramirez, J. A. (1989). "Detailing of stirrup reinforcement." ACI Struct. J., 86(5), 507-515.

Ang, A. H.-S., and Tang, W. H. (1976). Probability concepts in engineering planning and design. Vol. I. Basic principles, Wiley, New York.

Angelakos, D., Bentz, E. C., and Collins, M. P. (2001). "Effect of concrete strength and minimum stirrups on shear strength of large members." J. Struct. Eng., 98(3), 290-300.

ATENA. (2005). "ATENA-nonlinear analysis software.” Červenka Consulting, Prague.

Bažant, Z. P. (1984). "Size effect in blunt fracture: Concrete, rock, metal." J. Eng. Mech., 110, 518-535.

Bažant, Z. P. (1997). "Fracturing truss model: Size effect in shear failure of reinforced concrete." J. Eng. Mech., 123(12), 1276-1288.

Bažant, Z. P. (2005). Scaling of structural strength, 2nd Ed., Elsevier, London.

Bažant, Z. P., Caner, F. C., Carol, I., Adley, M. D., and Akers, S. A. (2000). "Microplane model M4 for concrete: I. Formulation with workconjugate deviatoric stress." J. Eng. Mech., 126(9), 944-953.

Bažant, Z. P., and Jirásek, M. (2002). "Nonlocal integral formulations of plasticity and damage: Survey of progress." J. Eng. Mech., 128(11), 1119-1149.

Bažant, Z. P., and Kazemi, M. T. (1991). "Size effect on diagonal shear failure of beams without stirrups." ACI J., 88(3), 268276.

Bažant, Z. P., and Kim, J.-K. (1984). "Size effect in shear failure of longitudinally reinforced beams." J. Am. Concr. Inst., 81, 456-468.

Bažant, Z. P., and Oh, B.-H. (1983). "Crack band theory for fracture of concrete." Mater. Struct., 16, 155-177.

Bažant, Z. P., and Pang, S.-D. (2007). "Activation energy based extreme value statistics and size effect in brittle and quasibrittle fracture." J. Mech. Phys. Solids, 55, 91-134. 
Bažant, Z. P., and Planas, J. (1998). Fracture and size effect in concrete and other quasibrittle materials, CRC Press, Boca Raton, FL.

Bažant, Z. P., and Sun, H.-H. (1987). "Size effect in diagonal shear failure: Influence of aggregate size and stirrups." ACI J., 84(4), 259-272.

Bažant, Z. P., and Xi, Y. (1991). "Statistical size effect in quasi-brittle structures: II. Nonlocal theory." J. Eng. Mech., 117(11), 2623-2640.

Bažant, Z. P., and Xiang, Y. (1997). "Size effect in compression fracture: Splitting crack band propagation.” J. Eng. Mech., 123(2), 162-172.

Bažant, Z. P., and Yu, Q. (2005a). "Designing against size effect on shear strength of reinforced concrete beams without stirrups: I. Formulation." J. Struct. Eng., 131(12), 1877-1885.

Bažant, Z. P., and Yu, Q. (2005b). "Designing against size effect on shear strength of reinforced concrete beams without stirrups: II. Verification and calibration." J. Struct. Eng., 131(12), 1886-1897.

Bažant, Z. P., and Yu, Q. (2006). "Reliability, brittleness, covert understrength factors, and fringe formulas in concrete design codes." J. Struct. Eng., 132(1), 3-12.

Bažant, Z. P., and Yu, Q. (2007). "Consequences of ignoring or mis-judging the size effect in concrete design codes and practice." Concrete Technology (Taiwan), 1(1), 29-55 (authorized republication, with updates, from Proc., 3rd Structural Engineers World Congress, Bangalore, 2007).

Bažant, Z. P., and Yu, Q. (2008). "Minimizing statistical bias to identify size effect from beam shear database." ACI Struct. J., 105(6), 685-691.

Bažant, Z. P., and Yu, Q. (2009). "Does strength test satisfying code requirement for nominal strength justify ignoring size effect in shear?" ACI Struct. J., 106(1), 14-19.

Bažant, Z. P., Yu, Q., Gerstle, W., Hanson, J., and Ju, J. W. (2007). "Justifiction of ACI 446 proposal for updating ACI code provisions for shear design of reinforced concrete beams." ACI Struct. J., 104(5), 601-610.

Becq-Giraudon, E. F. (2000). "Size effect on fracture and ductility of concrete and fiber composites." Dissertation, Northwestern Univ.

Bhal, N. S. (1968). "Über den Einfluss der Balkenhöhe auf Schubtragfähighkeit von einfeldrigen Stalbetonbalken mit und ohne Schubbewehrung." Dissertation, Universität Stuttgart.

Bresler, B., and Scordelis, A. C. (1963). Shear strength of reinforced concrete beams." Proc., J. Am. Concr. Inst., 60(1), 51-74.

Bresler, B., and Scordelis, A. C. (1966). "Shear strength of reinforced concrete beams-Series III." Rep. No. 65-10, Structures and Materials Research, Dept. of Civil Engineering, Univ. of California, Berkeley, CA.

Caner, F. C., and Bažant, Z. P. (2000). "Microplane model M4 for concrete: II. Algorithm and calibration.” J. Eng. Mech., 126(9), 954-961.

Chakravarti, I. M., Laha, R. G., and Roy, J. (1967). Handbook of methods of applied statistics, Vol. I, Wiley, New York, 392-394.

Comité Euro-International du Béton (CEB). (1990). CEB-FIP model code 1990.

Duckett, W. (2005). "Risk analysis and the acceptable probability of failure." Structural Engineer, August, 25-26.

Elzanaty, A. H., Nilson, A. H., and Slate, F. O. (1986). "Shear capacity of reinforced concrete beams using high-strength concrete." Proc., J. Am. Concr. Inst., 83(2), 290-296.

Frosch, R. J. (2000). "Behavior of large-scale reinforced concrete beams with minimum shear reinforcement." ACI Struct. J., 97(6), 814-820.

Iguro, M., Shioya, T., Nojiri, Y., and Akiyama, H. (1985). "Experimental studies on shear strength of large reinforced concrete beams under uniformly distributed load." Concrete Library Int. of JSCE, No. 5 (translation from Proc., JSCE, No. 345/V-1, August 1984), 137-146.

Japan Society of Civil Engineers (JSCE). (1986). Standard specification for design and construction of concrete structures, Part 1 [Design]. Tokyo.

Johnson, M. K., and Ramirez, J. A. (1989). "Minimum shear reinforcement in beams with higher strength concrete." ACI Struct. J., 86(4), 376-382.

Kani, G. N. J. (1967). "How safe are our large reinforced concrete beams?" Proc., J. Am. Concr. Inst., 64(31), 128-141.
Karayiannis, C. G., and Chalioris, C. E. (1999). "Experimental investigation of the influence of stirrups on the shear failure mechanism of reinforced concrete beams." Proc., 13th Hellenic Conference on Concrete, Rethymnon, Greece, 1, 133-141 (in Greek).

Kong, P. Y. L., and Rangan, B. V. (1998). "Shear strength of highperformance concrete beams." ACI Struct. J., 95(6), 667-677.

Krefeld, W. J., and Thurston, C. W. (1966). "Studies of the shear and diagonal tension strength of simply supported reinforced concrete beams." J. Am. Concr. Inst., April 1966, 451-476.

Lampert, P., and Thürlimann, B. (1969). "Torsion tests of reinforced concrete beams (Torsionsversuche an Stahlbetonbalken)." Bericht No. 6506-2, Institut für Baustatik, ETH, Zürich, June 1968, 101, and "Torsion-bending tests on reinforced concrete beams (Torsion-BiegeVersuche an Stahlbetonbalken)," Bericht No. 6506-3, Institut für Baustatik, ETH, Zürich, 116.

Leonhardt, F., and Walther, R. (1962). "Schubversuche an Einfeldrigen Stahlbeton-Balken mit und ohne Schubbewehrung zur Ermittlung der Schubtragfähigkeit und der Oberen Schubspannungsgrenze." Heft 151, Deutcher Ausschuss für Stahlbeton, W. Ernst, u. Sohn, Berlin, 66 (in German).

Lubell, A., Sherwood, T., Bentz, E., and Collins, M. P. (2004). "Safe shear design of large, wide beams." Concr. Int., 26(1), 67-78, with discussions (letter to ed.) by Bažant and Yu.

Mattock, A. H., and Wang, Z. (1984). "Shear strength of reinforced concrete members subject to high axial compressive stress." J. Am. Concr. Inst., May-June, 287-298.

McGormley, J. C., Cleary, D. B., and Ramirez, J. A. (1996). "The performance of epoxy-coated shear reinforcement." ACI Struct. J., 93(5), 531-537.

Melchers, R. E. (1987). Structural reliability, analysis and prediction, Wiley, New York.

Mörsch, E. (1922). "Der eisenbetonbau-Seine theorie und anwendung." Reinforced concrete construction-Theory and application, Wittwer, Stuttgart, 5th Ed., Vol. 1, Part 1, 1920 and Part 2, 1922.

Mphonde, A. G., and Frantz, G. G. (1985). "Shear tests of high-and low-strength concrete beams with stirrups." High-strength concrete, SP-87, H. G. Russell, ed., American Concrete Institute, Farmington Hills, MI, 179-196.

NKB. (1978). "Nordic committee for building structures. Recommendation for loading and safety regulations for structural design." NKB Rep., No. 36.

Okamura, H., and Higai, T. (1980). "Proposed design equation for shear strength of reinforced concrete beams without web reinforcement." Proc., Japanese Society of Civil Engineers, 300, Japanese Society of Civil Engineers, Tokyo, 131-141.

Placas, A., and Regan, P. E. (1971). "Shear failure of reinforced concrete beams.” Proc., J. Am. Concr. Inst., 68(10), 763-773.

Podgorniak-Stanik, B. A. (1998). "The influence of concrete strength, distribution of longitudinal reinforcement, amount of transverse reinforcement and member size on shear strength of reinforced concrete members." M.A.Sc. thesis, Dept. of Civil Engineering, Univ. of Toronto, 771.

Rajagopalan, K. S., and Ferguson, P. M. (1968). "Exploratory shear tests emphasizing percentage of longitudinal steel." J. Am. Concr. Inst., August, 634-638.

Reineck, K.-H., Kuchma, D. A., Kim, K. S., and Marx, S. (2003). "Shear database for reinforced concrete members without shear reinforcement." ACI Struct. J., 100(2), 240-249.

RILEM Technical Committee QFS. (2004). "Quasibrittle fracture scaling and size effect-Final report." Mater. Struct., 37(272), 547-586.

Ritter, W. (1899). "Die Bauweise Hennebique." Schweizerische Bauzeitung Zürich, 33(7), 59-61.

Roller, J. J., and Russell, H. G. (1990). "Shear strength of high-strength concrete beams with web reinforcement." ACI Struct. J., 87(2), 191-198.

Russo, G., Somma, G., and Angeli, P. (2004). "Design shear strength formula for high strength concrete beams." Mater. Struct., 37, 680-688.

Sarsam, K. F., and Al-Musawi, J. M. S. (1992). "Shear design of high-and normal-strength concrete beams with web reinforcement." ACI Struct. $J ., 89(6), 658-664$. 
Shah, A., and Ahmad, S. (2007). "An experimental investigation into shear capacity of high strength concrete beams." Asian J. Civil Eng. (Building and Housing), 8(5), 549-562.

Shioya, T., and Akiyama, H. (1994). "Application to design of size effect in reinforced concrete structures." Size effect in concrete structures (Proc., Japan Concrete Institute Int. Workshop, Sendai), H. Mihashi, H. Okamura, and Z. P. Bažant, eds., Spon, London, 409-416.

Snedecor, G. W., and Cochran, W. G. (1989). Statistical Methods, 8th Ed., Iowa State Univ. Press.

Swamy, R. N., and Andriopoulos, A. D. (1974). "Contribution of aggregate interlock and dowel forces to the shear resistance of reinforced beams with web reinforcement." Shear in reinforcement concrete, SP-42, American Concrete Institute, Farmington Hills, MI, 129-166.

Tan, K. H., and Cheng, G. H. (2006). "Size effect on shear strength of deep beams: Investigating with strut-and-tie model.” J. Struct. Eng., 132(5), 673-685.

Tan, K. H., and Lu, Y. (1999). "Shear behavior of large reinforced concrete deep beams and code comparisons." ACI Struct. J., 96(5), 836-846.

Tompos, E. J., and Frosch, R. J. (2002). "Influence of beam size, longitudinal reinforcement, and stirrup effectiveness on concrete sheaer strength." ACI Struct. J., 99(5), 559-567.
Walraven, J., and Lehwalter, N. (1994). "Size effect in short beams loaded in shear." ACI Struct. J., 91(5), 585-593.

Weibull, W. (1939). "The phenomenon of rupture in solids." Proc., Royal Swedish Institute of Engineering Research, 153, Stockholm, $1-55$.

Weibull, W. (1951). "A statistical distribution function of wide applicability." J. Appl. Mech., 18, 293-297.

Xie, Y., Ahmad, S. H., Yu, T., Hino, S., and Chung, W. (1994). "Shear ductility of reinforced concrete beams of normal and high-strength concrete." ACI Struct. J., 91(2), 140-149.

Yoon, Y., Cook, W. D., and Mitchell, D. (1996). "Minimum shear reinforcement in normal-, medium-, and high-strength concrete beams." ACI Struct. J., 93(5), 576-584.

Zararis, P. D. (2003). "Shear strength and minimum shear reinforcement of reinforced concrete slender beams." ACI Struct. J., 100(2), 203-214.

Zararis, P. D., and Papadakis, G. (1999). "Influence of the arrangement of reinforcement on the shear strength of RC beams." Proc., 13th Hellenic Conference on Concrete, Vol. I, Rethymnon, Greece, 110-119 (in Greek). 